\title{
Online Ordering and Recommender System of Combine Harvester Parts and Equipment with 3D Modelling and Augmented Reality Brochure for BLAZE Equifarm and General Merchandise
}

\author{
Mark Jezter Ballesteros, Rachel Ann Cartujano, Dhanna Evaldez, Jomerson Macutay, \\ Jay-ar P. Lalata, Heintjie N. Vicente ${ }^{+}$, and Ace C. Lagman \\ FEU Institute of Technology, Philippines
}

\begin{abstract}
Agriculture has a big contribution in the life of most of the residents of Isabela having rice as the main crop. Having a large farm cannot be easily harvested manually so using a harvester machine helps the farmers get the rice and sell immediately without hustle. Through this, researchers aim to provide an easier and more comfortable way of purchasing harvester parts to the consumers without going on the physical store. This online ordering with recommender system displays the products and suggest relevant items to consumers. The integration of augmented reality in the physical brochure shows the 3D animations and descriptions of the 10 major parts of the machine which gives the consumers the knowledge about a certain part before it will be used in farm operations. In summary, the developed system is aimed at giving agricultural marketing information to all the farm owners in Isabela as well as to help increase the sales of the company.
\end{abstract}

Keywords: online ordering, harvester machine, 3D animation, recommender system, augmented reality

\section{Introduction}

Technological advancements have greatly affected the web-based eCommerce world by changing how customers associate with the products online and tend to shop more at a lower cost. With the help of getting items conveyed into someone's home, shopping online is becoming a vital piece of modern life. Competitive marketing, along with having a strategic plan, and a skilled workforce aside, the eCommerce associations hold and relied upon the new technology up to date. It helps people buy needs effortlessly using these technological advancements. Customers can track orders, can get anything, and find the best deals at the click of a button. With this advancement, new business opportunities are developing.

With online ordering with a recommender system on board, the owner will help its customers to experience the process of purchasing harvester parts and equipment online. Thus, this shows that the business values the time of their customers. An online ordering with a recommender system does ensure a good web presence that would make the business bring more customers and boost the business economic growth by replacing inefficient order phase.

\section{Literature}

The e-commerce industry is famous as a digital marketplace in 2018 due to the high net record of Filipino shoppers online. A total of 67-million Filipinos were active during this time, according to the Internet World Stats, and that a total of $12 \%$ increase every year. Thus, this means that in terms of social media use and time spent online, the country was ranked first countries worldwide and believes that this country would be an ideal place for e-commerce to thrive stated by Zialcita (2019).

Harvesters, combine harvesters, mechanical threshers, and even winnowers were introduced to improve working timeliness and minimize the job. The mentioned operated machines were subsequently adopted by tractor-drawn harvester type of machine. When it comes to harvesting sheaves, this can be done

Heintjie N. Vicente. Tel.: +639276604923.

E-mail address: hnvicente@feutech.edu.ph 
mechanically or manually threshed. But there may be difficulty in farming or threshing if this modern technical equipment is used in waterlogged fields, so caution was also required. Due to the shortage of farmworkers, it helps to prefer and use the harvester machines. just like a self-propelled harvester machine or operated tractor where can be used in wet or dry puddled fields (Samaddar et al, 2017).

People tend to spend more time using mobile phones than personally going to the mall. It will be a lot easier and less hassle for the customer. People who buy online or anywhere else on the online shopping platform are undeniably increasing. Furthermore, the study of Maalala, Muya, and Novenario (2018) stated that more than a total of 875-million are buyers who are purchasing products online, maybe because most are just discovering online shopping, or maybe recommended by an acquaintance. It is natural for Filipinos to be persuaded especially if the information received about a business is enticing.

In order to find product information through online reviews, many consumers use the Internet. Other consumers and experts give these ratings. Reviews from users are becoming increasingly common. Recommended systems offer an important solution to the issue of information overload, as the business provides users with more practical and customized information. The Internet Research \& Recommendation program is a public or private internet destination that offers a peer-to-peer research forum for the various requirements of its participants (Reddy and Wang, 2014).

\section{Methodology}

\subsection{Requirement Specification}

With the help of data gathering and researching information, developers can understand how the system works and develop for BLAZE Equifarm and General Merchandise. It is important to understand the feasibility of the project.

\subsection{Project Design}

Figure 1 illustrates the system architecture of the developed project, and shows the structure and functionality of the system. Using a computer device, the user needs to connect to the internet to access the database to see and record different data.

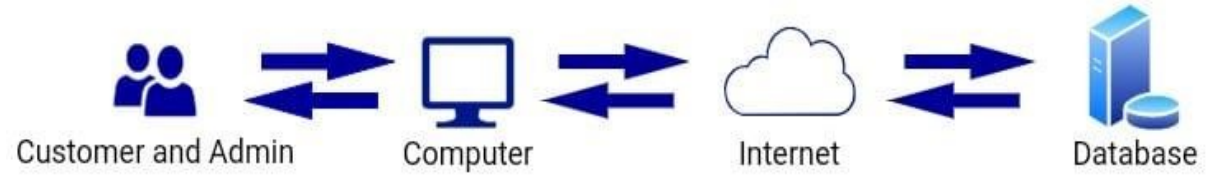

Fig. 1: System Architecture of the Developed System

The context flow diagram shown in figure no. 2 is the top-level process that summed up the external entities. These external entities were in a relation to the function of the system in which the top-level process accommodates. Each entity's functionality was outlined with the use of data flow.

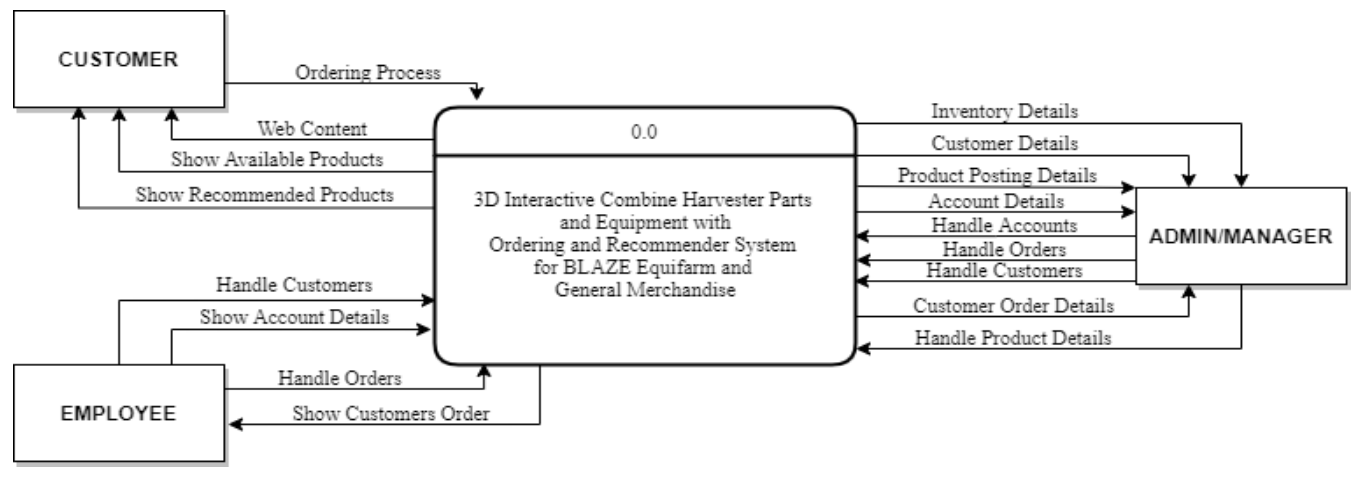

Fig. 2: Context Diagram

It demonstrates how data is being processed and transferred through the system concerning its inputs and outputs. The following process shows an activity that is done by the customers, administrator or manager, and the item deliverers. The customers can see the available or the on-stock harvester parts and 
equipment online. The administrator can edit the available item details, as well as provide reports on the most purchased brand of harvester part and equipment. The delivery staff on the other hand can deliver the item ordinarily. The customers can buy harvester parts or equipment using the business online ordering system with the recommender and also can manage order transaction registering, providing valid information for the next transaction, and adding chosen items that can be viewed in a 3D model.

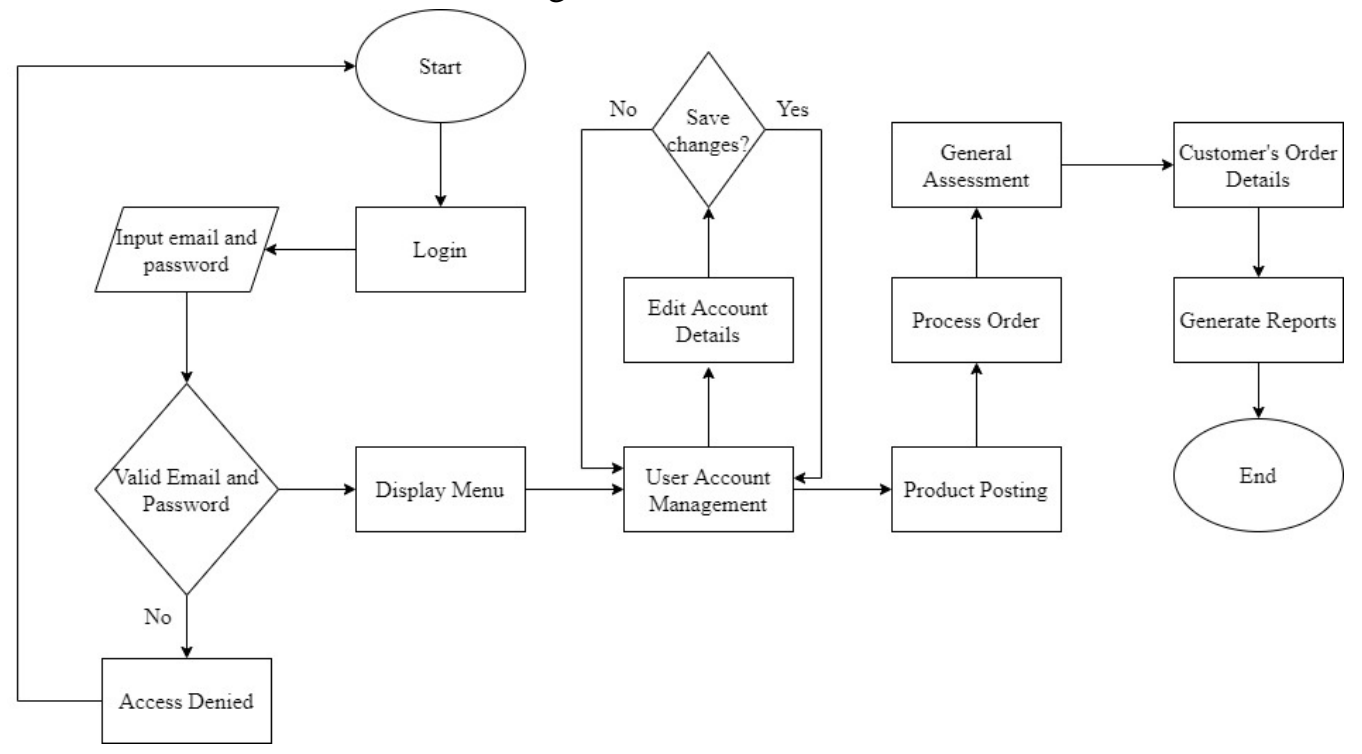

Fig. 3: Developed System Admin or Manager's Flowchart

Figure 3 depicts the admin or manager's login process in a flowchart diagram. Admin or manager must first $\log$ in to access the system with its full features. Collection of the email and password of the assigned admin will be collected automatically by the system. When a piece of valid information such as the correct email and password was entered, the admin or manager will access the system and will be redirected to the interface of the system.

The different figures below are the user interfaces of the developed system. The dashboard of the administrator's accounts management shown in figure no 5 contains the information of the administrators of the business. This has action buttons where the admin account can be edited, viewed, and deactivated. For the account management dashboard for employee given in figure no 4 is similar to the administrator dashboard. It also has action buttons where the super admin can add, edit, view, and deactivate an employee account. And for the reports management dashboard seen in figure 6, is the system reports management dashboard which contains lists of registered customers, orders, products, and sales. The data collected are the data that occurs in the use of the system.

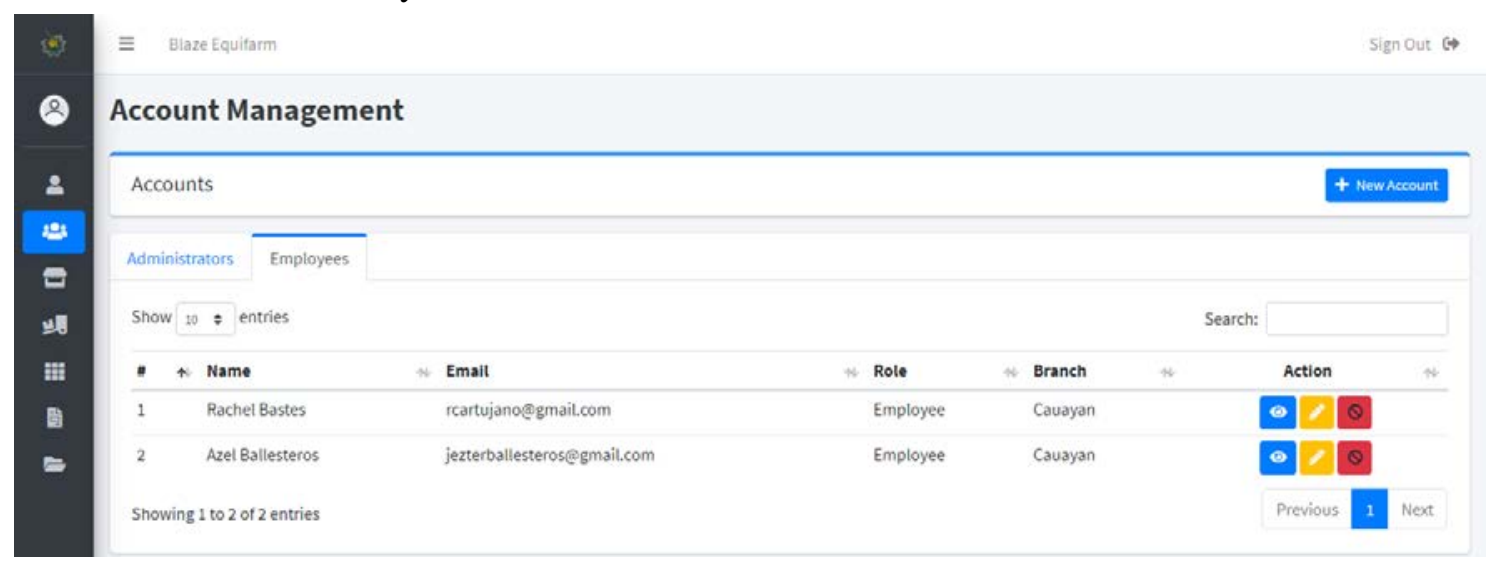

Fig. 4: Account Management Dashboard for Employee 


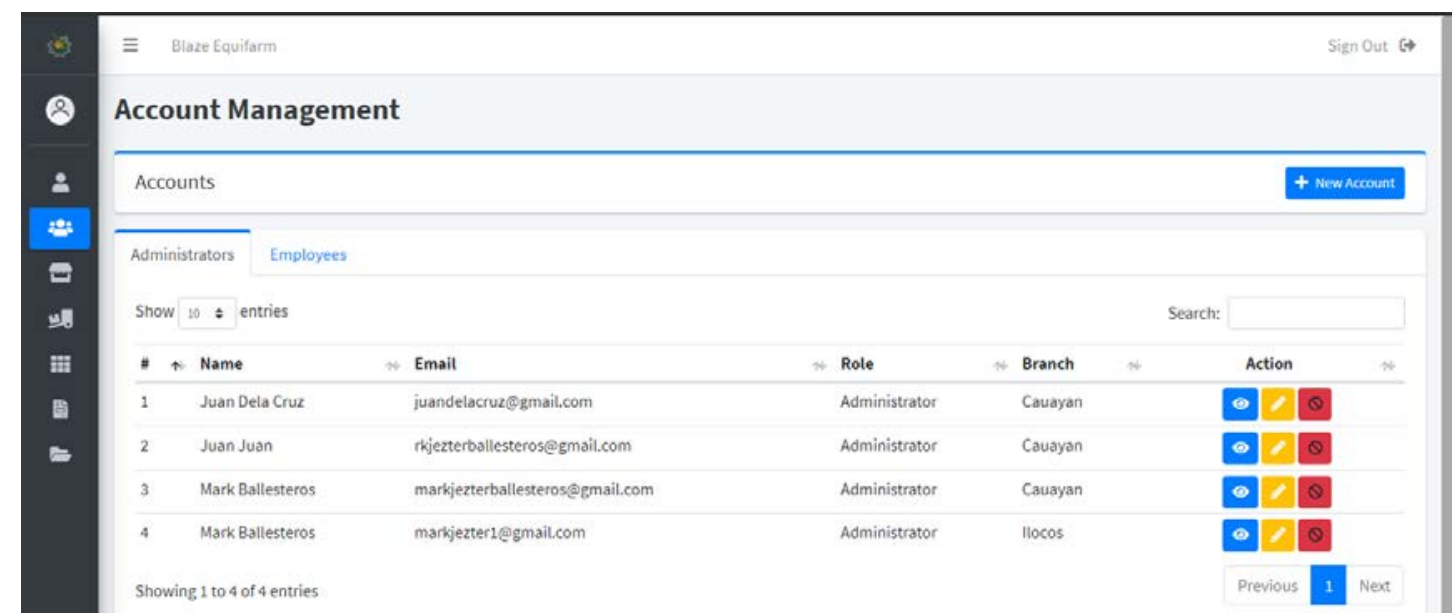

Fig.5: Account Management Dashboard for Administrator

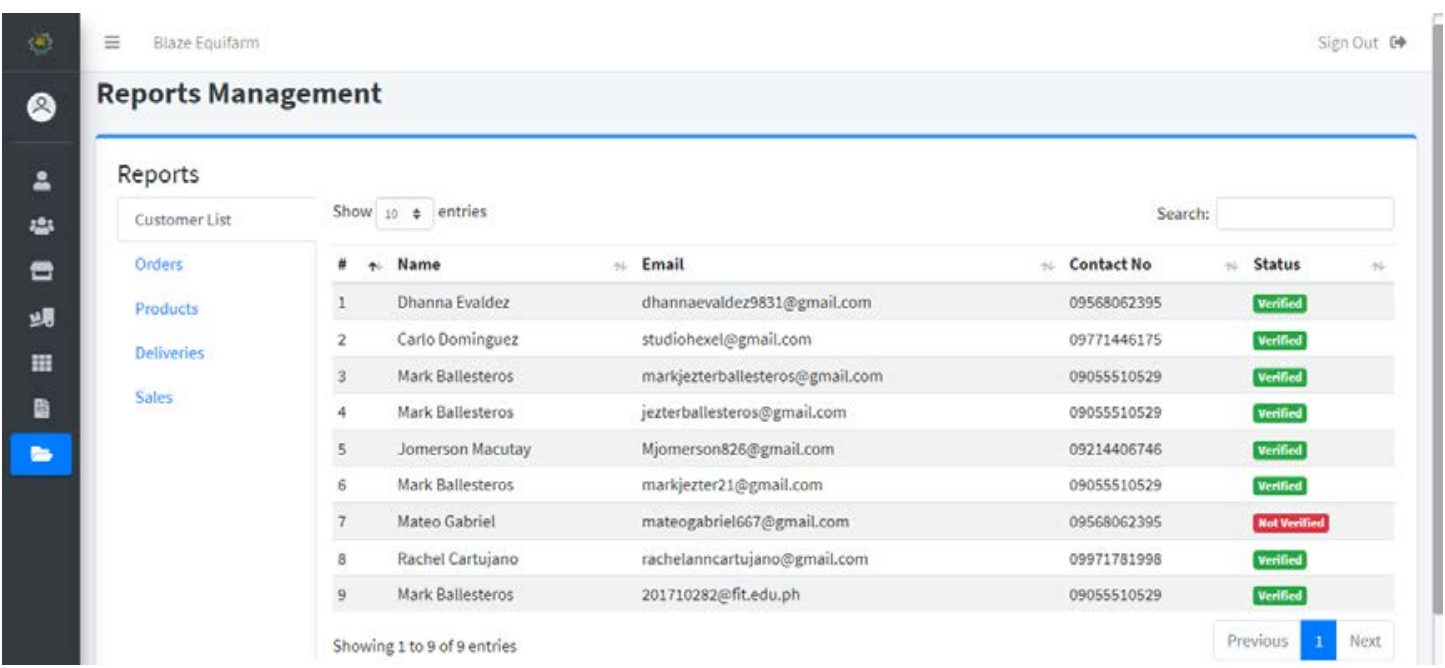

Fig. 6: Reports Management Dashboard

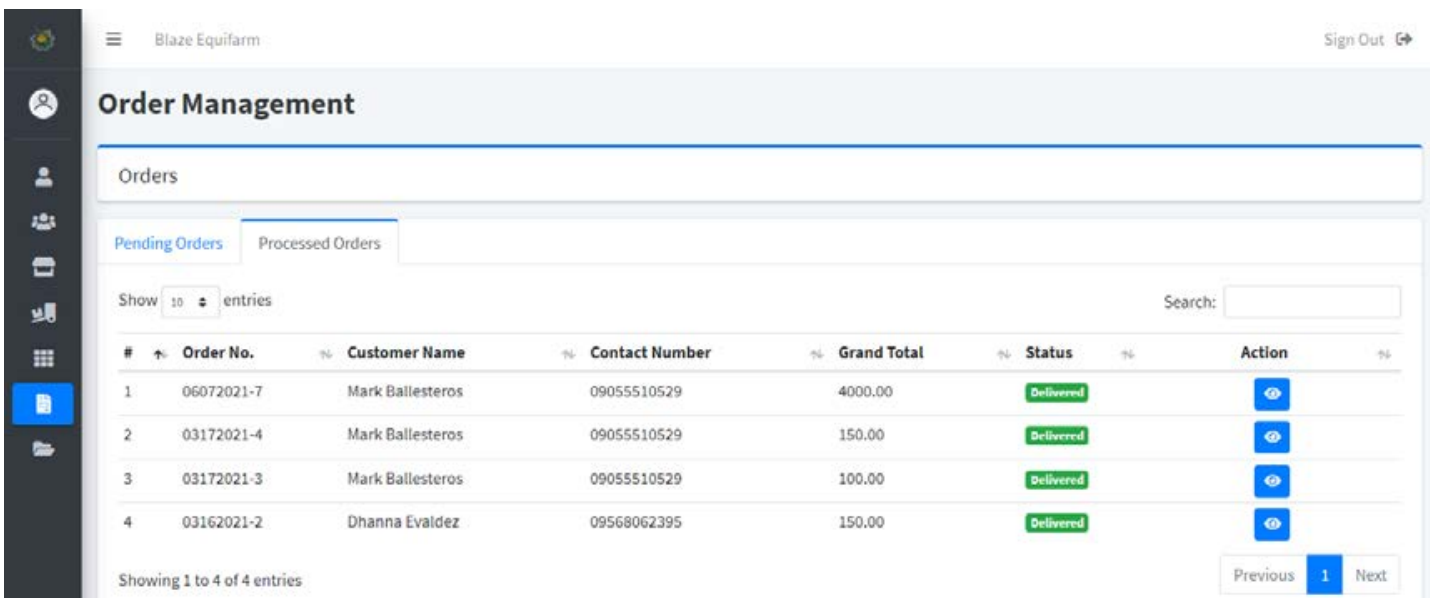

Fig. 7: Successful Orders

Figure 8 represents the graphical representation of scrum methodology. This method was followed by the researchers during the development of the system. It was constructed using different programming languages such as CSS, JavaScript, and PHP, CodeIgniter, HTML, XAMPP, MyPhpAdmin, and Sublime. The manager or the admin could have the ability to perform the adding, editing, deleting, resetting, and updating of the entire system. For similarity checking, the researchers verified if the system would work on the following hardware specifications and programming with different web programs. This helped the researchers to fathom whether the system is suitable for most of the systems. In terms of technology, the system can be used with a web browser. The back end of this project used MySQL and PHP scripting languages. 


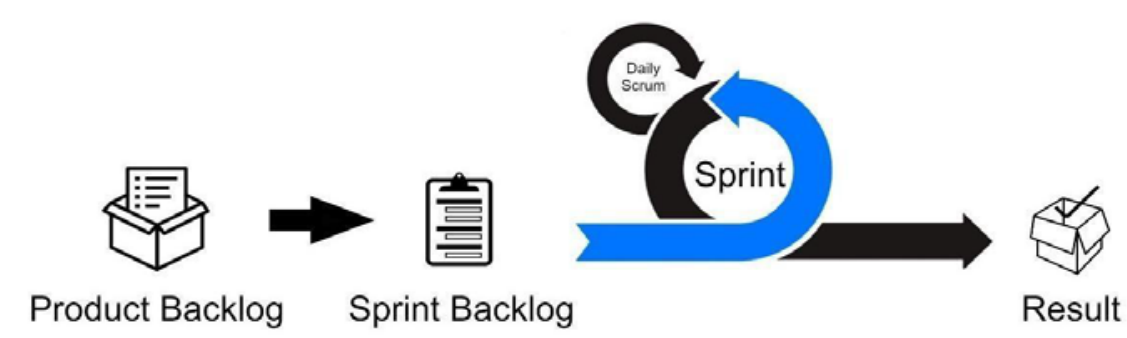

Fig 8: Scrum Methodology

\subsection{Evaluation}

In this study, the sampling technique used was purposive sampling. The target respondents were 30 IT and Non-IT students who participated in evaluating the developed system in different software evaluation criteria such as Functionality, Usability, Reliability, Performance, and Security.

\section{Results and Discussion}

The collected data are the responses of the respondents who have performed the software testing and their perceptions to the website. The questions used in the survey were generated by using the four models (the Functionality, Usability, Reliability, Performance, and Security) which are known for clarifying the quality attributes of a software. As for the testing part of the system, three types of test scripts were used and these are the Alpha, Beta, and the User Acceptance Testing. These results were needed to determine the status of the website. And the results obtained will also be used as a basis for possible system improvements for future use.

Table 1: Summary of weighted mean

\begin{tabular}{|c|c|c|}
\hline Criteria & Weighted Mean & Response Description \\
\hline Functionality & 4.67 & Strongly Agree \\
\hline Usability & 4.61 & Strongly Agree \\
\hline Reliability & 4.64 & Strongly Agree \\
\hline Performance & 4.62 & Strongly Agree \\
\hline Security & 4.66 & Strongly Agree \\
\hline Overall & $\mathbf{4 . 6 4}$ & Strongly Agree \\
\hline
\end{tabular}

Table 1 presents the calculated weighted mean based on the results obtained in answering the survey conducted by the respondents. Integration of IT and Non-IT students as the basis for the survey results. The table shows that the functionality of the system is in the lead where many of the respondents strongly agree followed by security which reached a total of 4.66. Generally, it reaches 4.64 for the overall mean which is covered by strongly agree of the Likert scale degree.

\section{Conclusion}

BLAZE Equifarm and General Merchandise provide a huge variety of machines and farm equipment that helps farmers to operate easier by also providing repair services to a specific machine the customer wants to restore. The researchers developed a website wherein customers can order without going to the physical store and a system that can recommend trend products using Apriori algorithm and market basket analytics which would help customers choose products based on their budget. The researchers successfully developed an online ordering and recommender system of combine harvester parts and equipment with 3D modeling and augmented reality brochures for BLAZE aquafarm and general merchandise that would help the marketing process of the company in terms of sales. Augmented reality is available for them to understand how the 
website interacts during the process. AR provides additional information on each item and as well as give the customers a unique experience to easily visualize an object in a personalized context. And it would help attract new customers and retain the existing ones.

\section{Recommendation and Future Works}

The researchers successfully developed an online ordering and recommender system of combine harvester parts and equipment with 3D modeling and augmented reality brochures for BLAZE aquafarm and general merchandise that would help the marketing process of the company. In line with this, the researchers recommend the next developer or future researchers of the same study to: Further improve the project for the capstone, the researchers would like to recommend an additional system feature or module that can improve the system which will serve as a big help and to have a better system. Second, to recommend further improving the user interface of the system, the tables of collected data, navigations, and such that can be fixed in the system to make it look even better and attractive. Third, to further expand the data visualization of the system and filtering of reports, and since the store has four branches, researchers want to recommend expanding the system where it can handle and be used by four branches.

\section{References}

[1] Adrian, Emily, \& Ng, A. (2019, December 18). Future of Ecommerce: 10 International Growth Trends (Updated 2020). Retrieved from https://beeketing.com/blog/futureeecommerce-2019/.

[2] Combine Harvesters. (n.d.). Retrieved from https://www.sciencedirect.com/topics/agricultural-andbiologicalsciences/combine-harvesters.

[3] Combine Harvesters Market Share, Size, Analysis: Forecast (2019-2024). (n.d.). Retrieved from https://www.mordorintelligence.com/industry-reports/combineharvester-market.

[4] Dapas, C., Purwanto, E., Sitorus, T., \&Ihalauw, J. J. O. I. (n.d.). The effect of service quality and website quality of ... Retrieved from

[5] https://www.researchgate.net/publication/331502242_The_effect_of_service_quality_and_website_q uality_of_zaloraCom_on_purchase_decision_as_mediated_by_purchase_intention.

[6] Ecommerce Marketing in 2019: Personas, Advertising Channels \& More. (2019, August 22). Retrieved from https://www.bigcommerce.com/blog/ecommerce-marketing/

[7] Experts, T. N. S. (2019, December 20). E-Commerce is Growing at an Unprecedented Rate All over the Globe. Retrieved from https://thenextscoop.com/e-commerce-isgrowing-at-an-unprecedentedrate-all-over-the-globe/

[8] Jiradilok, T., Malisuwan, S., Madan, N., \&Sivaraks, J. (2014, February). "The impact of customer satisfaction on online purchasing: A case study analysis in thailand”, Journal of Economics, Business and Management, Vol. 2, No. 1. Retrieved from

[9] http://www.joebm.com/papers/89A00007.pdf?fbclid=IwAR14u12supnsMkYTgcSzWdwDo7e2VqiJJ7PfVC8Owr 1uPu2ICaotA6M

[10] Kemp, S., \&Moey, S. (2019, September 18). Ecommerce in The Philippines in 2019 DataReportal - Global Digital Insights. Retrieved from https://datareportal.com/reports/digital-2019-ecommerce-inthe-philippines.

[11] Maala, M. G. O., Novenario, J. D. G., \& Muya, G. R. (n.d.). COMMUNICATION TOOLS OF E-COMMERCE: THE CASE OF LAZADA, 3, 18-18. Retrieved from http://pulaguna.edu.ph/wp-content/uploads/2018/12/2COMMUNICATION-TOOLS.pdf 